\title{
Los Rubén Darío de Juan Ramón Jiménez. Retrato con el mar de fondo
}

\author{
Alfonso GARCíA MORALES \\ Universidad de Sevilla \\ alfgm@us.es
}

\begin{abstract}
RESUMEN
El retrato literario "Rubén Darío (1940)" que Juan Ramón Jiménez publicó ese año en Letras de México y que incluyó en Españoles de tres mundos (1942), es posiblemente el texto más significativo de los muchos que a lo largo de su vida dedicó a Darío, de quien se consideraba discípulo y heredero. No en vano Juan Ramón también pensó en situarlo en un privilegiado primer lugar dentro de su proyecto inacabado Mi Rubén Darío. El presente artículo reconstruye e interpreta la génesis, evolución y significado de la imagen central del retrato: la de un "Darío marino", que aparece ya en el primer texto juanramoniano sobre Darío, de 1903, y que persiste, a través de distintas variaciones, durante más de cuarenta años. Además, se dilucidan las sorprendentes relaciones que esta imagen literaria presenta con la iconografía dariana.
\end{abstract}

Palabras clave: Juan Ramón Jiménez, Rubén Darío, retrato literario, literatura y mar, iconografía dariana

The different constructions of Rubén Darío by Juan Ramón Jiménez. Portrait with a background sea

\begin{abstract}
The literary portrait "Rubén Darío (1940)" that Juan Ramón Jiménez published that year in Letras de México and that later he included in the work Españoles de tres mundos (1942), it is probably the most significant of the texts he devoted to Darío, whom he considered his disciple and successor. As a matter of fact, Juan Ramón Jiménez conceived a special place for him in his unfinished project Mi Rubén Dario. The present paper reconstructs and illustrates the origin, evolution, and meaning of the central image in the portrait: A Rubén Darío associated with the sea. This image already appeared in the first text dedicated to Darío in 1903, and remained, through different variations, for over forty years. Moreover, this analysis decodes the surprising relationships between this image and the iconography associated to Rubén Darío.
\end{abstract}

Key words: Juan Ramón Jiménez, Rubén Darío, literary portrait, sea and poetry, Ruben Dario's iconography. 
Entre los contemporáneos españoles de Darío posiblemente ningún otro tuvo con él una relación literaria tan intensa, decisiva, persistente y compleja, en la que se cumpliera con tanta claridad y también con tantos matices el tema del maestro y el discípulo, como Juan Ramón Jiménez. El testimonio fundamental de esa relación es Mi Rubén Dario, un libro larguísimamente planeado pero nunca acabado de Juan Ramón, el único que pensó dedicar en exclusiva a un poeta, y que conocemos gracias a la reconstrucción aproximada que Antonio Sánchez Romeralo llevó a cabo en 1990. Mi Rubén Dario (en adelante MRD) contiene cartas, poemas y críticas intercambiadas por el maestro Darío y su discípulo Juan Ramón, así como los principales textos en los que el heredero Juan Ramón rememoró o recreó a su Darío. Es un libro de gran valor documental pero que hay que entender dentro de la obra total de Juan Ramón, en el que puede observarse cómo éste fue siempre fiel a una idea trascendentalista o religiosa del arte, y cómo, a partir de la figura fundadora de Darío, desplegó sus estrategias de autoridad en el cambiante campo de la modernidad poética en español.

El presente trabajo continúa otros anteriores (García Morales y García Gutiérrez 2002 y García Morales 2014) y tiene como eje fundamental el retrato literario "Rubén Darío (1940)". Juan Ramón lo escribió durante su exilio en Florida, lo adelantó en Letras de México $\left(\mathrm{n}^{\circ} 16,15\right.$ de abril 1940) y en principio lo destinó al libro de retratos literarios Españoles de tres mundos (1942), pero también pensó ponerlo en un significativo primer lugar dentro de Mi Rubén Dario. Es una reescritura de su serie de textos dedicados a Darío, varios de ellos retratos, algunos inéditos, a los que de hecho empieza refiriéndose: " $5^{\circ}, 7^{\circ}, 13^{\circ}, 17^{\circ}$ Rubén Darío mío. ¡Tanto Rubén Darío en mí; tan vivo siempre, tan igual y tan distinto; siempre tan nuevo! Ninguna de mis siluetas sucesivas (Mi Rubén Dario, Contra y por Rubén Dario, Rubén Darío español, etc.) es la siguiente" (MRD 43) ${ }^{1}$. Lo igual y sobre todo lo distinto de este Darío del 40 es que, para emplear palabras propias de Juan Ramón, el "lado" o "perfil esencial" que se destaca es el de un Darío marino: "Hoy, más cerca de su León y su cuerpo deshecho, el capricho de la onda incesante de las figuraciones trae a mi imaginación un Rubén Darío marino" (MRD 43). Un Darío "raro monstruo humano marino", "ente de mar más que de tierra", "capitán de navío" lírico, "nostálgico navegante", asociado a un "fondo" o paisaje también esencial: el mar elemental y mitológico, el Atlántico, Pacífico y Mediterráneo surcados por el poeta y que se resumen simbólicamente en el mar de Citeres, con sus olas y caracolas, su Venus y su isla final. Mi propósito es situar sucintamente el retrato entre los múltiples escritos sobre Darío de Juan Ramón, interpretarlo dentro

${ }^{1}$ El intento más ambicioso y logrado hasta ahora de ordenar los distintos "Daríos" de Juan Ramón creo que fue realizado por Ángel Crespo en un excelente y algo olvidado artículo (Crespo 1981: 47-87), que cabe seguir discutiendo y completando desde diferentes ángulos. Esto es lo que, a su vez, se intenta hacer aquí. 
de su obra en marcha, unitaria y sucesiva, en cambio permanente, una de cuyas grandes metáforas es el mar, y seguir la génesis, evolución y significado de la imagen del Darío marino.

Cuando Ernesto Mejía Sánchez rescató el cuento dariano "Historia del mar", dedicado al chileno Alberto del Solar, e indagó en las relaciones de éste con Darío, también creyó encontrar la "fuente" de inspiración de Juan Ramón. Su retrato del 40 se habría basado en la necrológica que Del Solar dedicó a Darío y cuyo tema es la compartida afición literaria por el Océano. La necrológica se publicó en España en 1917 y Juan Ramón pudo, efectivamente, conocerla (Solar 1917). Aunque tanto o más probable es que conociese el prólogo que el propio Darío había escrito veinte años antes para El mar en la leyenda y en el arte (1897) de Del Solar, y que había sido a su vez rescatado en 1938 por Saavedra Molina. En él Darío hace una declaración sobre su predilección y sintonía con el mar - corazón rítmico del cosmos, materialización del misterio profundo de la poesía y sublime escenario mitológico de la aventura poética—, que tuvo múltiples desarrollos en su literatura:

Yo, que amo con profundo amor ese gran corazón del mundo que no cesa de palpitar, como el corazón del hombre, más de una vez al recorrer estas bellas páginas, he volado con mi espíritu a la orilla del Mar, soberano y sensitivo, venerable y trágico, y le he saludado como un ser de misterio y maravilla, cuna de la Rosa Olímpica, Venus, y dominio de la Rosa Mística, María, Maris Stella (Darío 1938: 78).

Son, en realidad, muchas las sugestiones que a lo largo de los años Juan Ramón pudo recibir sobre el vínculo de Darío y el mar, pero estas no harían más que confirmar una intuición muy personal y temprana, que nace de sus primeras lecturas de Darío y que, de hecho, está ya formulada en el primer texto que publicó sobre él en 1903.

Debo recordar aquí que Juan Ramón descubrió y conoció a Darío durante la segunda estancia de éste en España, entre 1899 y 1900. Fue su encuentro literario decisivo, el que con más fuerza evocó y mitificó siempre. En medio de la pobre literatura española del momento, Darío representó el primer maestro vivo, el primer modelo contemporáneo auténticamente renovador, el que revolucionó, elevándolo, su concepto de la poesía. Juan Ramón contó muchas veces cómo, animado por su entonces amigo Francisco Villaespesa, viajó de Moguer a Madrid, a conocer a Darío, a "luchar" por el modernismo y a publicar su primer, inmaduro y precipitado poemario, que finalmente apareció dividido en dos: Ninfeas y Almas de violeta. El contacto fue breve. A los quince días Darío se marchó a la Exposición de París. Pese a su desconfianza de entonces sobre el futuro del modernismo español, Darío cumplió la promesa que le había hecho al entusiasta Juan Ramón y le envió un poema prólogo que apareció al frente de Ninfeas con el título "Atrio". Es un soneto de sentido iniciático, un soneto de preguntas. Un maestro interroga a un discípulo 
sobre su vocación antes de emprender la aventura heroica y religiosa de la vida artística. Comienza: “¿Tienes, joven amigo, ceñida la coraza/ para empezar, valiente, la divina pelea?", y se cierra con la bendición, el espaldarazo, la ordenación del nuevo caballero y sacerdote de la Belleza: "Sigue, entonces, tu rumbo de amor. Eres poeta./ La Belleza te cubra de luz y Dios te guarde" (MRD 9394). Juan Ramón siempre le agradeció a Darío su confianza y generosidad, consideró este poema una joya, la primera de su tesoro documental dariano, y le confirió un enorme valor simbólico. Por carta le aseguraba - y lo cumplió- que sería el único prólogo de otro a sus obras. Más tarde diría: "Aunque yo lo conservo y lo pongo al frente de mi obra, no es a mí a quien está dedicado, porque aún no existo yo, sino a algo que empieza" (Guerrero Ruiz 1999: 230).

Darío le estaba señalando el rumbo: un horizonte de amor hacia la Belleza. Pero orientación no es igual a camino personal, algo que Juan Ramón debía descubrir por sí mismo. Desde que se convirtió en el maestro del modernismo en América, Darío insistió ante las jóvenes generaciones que los únicos principios eran el culto a la Belleza y el desarrollo de la propia personalidad: "Yo no tengo literatura 'mía' para marcar el rumbo de los demás: mi literatura es mía en mí; quien siga servilmente mis huellas perderá su tesoro personal" (Darío 1967: 545). Y desde que volvió a España propugnó la necesidad de renovarse sin abandonar los valores de la tradición: "Una literatura de base nacional en la corriente del mundo" (Darío 1998: 408). Que es lo que harían algo después los mejores modernistas españoles, no sus seguidores sino los discípulos que supieron apropiarse creativamente de su mensaje.

A fines de 1902 Juan Ramón reanudó el contacto enviándole su nuevo poemario Rimas e invitándole a colaborar en Helios, la revista "seria", el Mercure de France de aquellos jóvenes poetas españoles que trataban de armonizar la novedad simbolista con la tradición nacional. También le pidió un ejemplar de Peregrinaciones, que él se encargaría de reseñar personalmente en el primer número. Darío, muy decepcionado ya de París, de sus posibilidades de reconocimiento en París, y mucho más confiado, tras la aparición de los Machado, en el futuro literario español, aceptó. Se inició entonces el periodo de colaboración propiamente dicha entre maestro y discípulo, que duró tres años y que tuvo sus puntos culminantes, primero entre 1903 y 1904, con la visita de Darío a Andalucía y la publicación de Tierras solares, y segundo, en 1905, con la estancia de Darío en Madrid y la publicación de Cantos de vida y esperanza.

En Helios Juan Ramón publicó sus primeros escritos sobre Darío, que empiezan por la prometida reseña a Peregrinaciones y que él concibe ya como adelantos de un libro en el que estudiaría la personalidad literaria del maestro, como el primerísimo germen de Mi Rubén Dario. Tienen un tono polémico característico del debate modernista: "Vosotros no sabéis, imbéciles, cómo canta este poeta" (MRD 170). Y por carta: "Tengo que decir mucho sobre usted, a estas pobres bestias madrileñas que, a lo que parece, cada día se dan menos cuenta de las cosas"; "Un día, con vida y con salud, haré un libro sobre usted... ipara estos brutos!" (Jiménez 
2006: 112 y 119). Mucho después señalaría: "Admirable' es la palabra alta de la época, 'imbécil' la baja. Con 'admirable' e 'imbécil' se hizo la crítica modernista" (Jiménez 1981: 83). Los imbéciles eran, desde luego, el público burgués y los críticos antimodernistas más cerriles y chabacanos. Pero en ese momento su defensa de Darío se extendía a críticos más cultos, como el académico Juan Valera, para él un escritor sin alma, incapaz de comprender el "azul", incluso a modernos antirubendarianos, como Unamuno o Rodó, y a todos los que, pensaba, se quedaban en la superficie, sin llegar al "fondo" de Darío. Frente a ellos quiso ofrecer una crítica penetrante y creativa, un Darío esencial y suyo, cercano a su propia poética simbolista. Creo que los puntos que le interesaron destacar desde el comienzo son los siguientes:

1) Darío no es un literato sino ante todo y sobre todo un poeta. En este tiempo Juan Ramón estuvo empeñado en recordar y recordarle al propio Darío su condición de gran poeta, y fue quien más le insistió en que, antes que nada, debía escribir poemas. Por ello lamentaba que tuviese que dedicar tanto tiempo y esfuerzo a escribir para medios periodísticos burgueses, incluso aunque el suyo fuera un "periodismo lírico" (MRD 166), algo a lo que seguirá aludiendo en su retrato del 40, cuando lo imagina "libre ya de aquel 'destierro' de periodista del mar, que era su melancolía" (MRD 45).

2) Darío es, además, un poeta interior y melancólico. Por eso hace ver que bajo su esteticismo y brillantez verbal hay un alma, por eso -pese a su naturaleza solar- lo asocia a su estirpe de poetas lunares y lo hermana con Verlaine.

3) Darío es un poeta español. "Uno de los más grandes poetas españoles de todos los tiempos", dice en su reseña (MRD 166). Y por carta: "Usted es el único gran poeta que hay actualmente en España” (Jiménez 2006: 132). La definición nacional de Darío nunca dejó de ser motivo de controversia. Para los americanistas no era el poeta de América, para los casticistas era antiespañol. Frente a estos últimos Juan Ramón lo reconoce como un poeta nutrido de la mejor tradición española, cada vez más vuelto a los temas españoles, más hermanado con los peninsulares.

Y 4) Juan Ramón presenta ya, sorprendentemente, a Darío como un poeta marino, como un peregrino, a veces perdido, que se acerca al mar elemental y eterno, y se reencuentra consigo mismo, con la vida y la poesía, la libertad y el absoluto. Es curioso que al reseñar Peregrinaciones Juan Ramón deje prácticamente de lado las crónicas sobre la Exposición parisina y las ciudades italianas, y sólo parezca fijarse en las pocas y últimas referencias que Darío hace ante el mar de Génova o Nápoles, para comentar: "Los ojos del gran poeta tienen su más largo éxtasis en las rojas apoteosis crepusculares por donde pasan los dioses, al rumor sinfónico del agua amarga y vieja del mar" (MRD 168). Sobre todo es sorprendente porque aunque más tarde disminuirá o negará lo español, lo verleniano o lo interior de Darío, nunca dejará de verlo como un gran poeta marino, un poeta cuya naturaleza y fondo último es el mar. 
Poco después Darío fue a pasar el invierno y a reponerse de una de sus crisis alcohólicas a la costa andaluza. De ese viaje de búsqueda real y simbólica del sol y del mar nació la serie de crónicas Tierras solares para La Nación, varias de las cuales se reprodujeron en Helios y fueron reunidas en libro por los editores de éste, Juan Ramón y sobre todo Gregorio Martínez Sierra. A diferencia de España contemporánea, Tierras solares significó el verdadero reencuentro de Darío con España y con su nueva poesía. Si el "Atrio" a Ninfeas había sido su apuesta por el aprendiz Juan Ramón, "La tristeza andaluza", la intensa reseña que dedicó a Arias tristes, fue su confirmación: Juan Ramón, decía, "ha aprendido a ser él mismo" (MRD 122). Y por carta: "Me alegro de ver despertar la poesía de España. Hay poetas nuevos que anuncian mucha belleza, y sueñan y dicen bellamente su soñar. $\mathrm{Y}$ entre ellos, dos, que quiero y prefiero: Antonio Machado y V., mi amable Jiménez" (MRD 97).

Las crónicas dedicadas a Málaga empiezan: "Escribo a la orilla del mar, sobre una terraza adonde llega el ruido de la espuma" (Darío 2001: 51). Y terminan: "Ella (Thalasa) vive en su misterio. Hace su eterna obra, cumple su destino infinito. Apenas si se comunica con los corazones que se acuerdan con la palpitación del suyo, con las mentes de los soñadores y pensadores que se hunden en lo insondable del tiempo y del espacio, con los buzos de Dios" (Darío 2001: 74). Juan Ramón escribe en Helios: "Como Rubén Darío está junto al Mediterráneo, andará por las playas midiendo el oleaje bravío y azul del mar con el oleaje de su alma" (MRD 169). Y por carta le solicita: “¿Qué versos ha hecho usted en Málaga? Supongo que el Mediterráneo no dejará de poner su azul en muchas rimas de usted. ¿Por qué no me manda a Helios algo de ese mar?" (Jiménez 2006: 130). Los poemas que estaba escribiendo eran su autorretrato "Yo soy aquel..." y la antiimperialista "Oda a Roosevelt", dos piezas claves para la configuración de Cantos de vida y esperanza. La primera la mandó a la revista Alma española de Azorín y la segunda, a Helios. También es curioso que cuando Juan Ramón la publique y comente, no mencione su mensaje político (algo que sí hará mucho después, en Estados Unidos) sino que siga desarrollando su intuición, su obsesión por el Darío marino. Las estrofas de la oda "están aprendidas en el trueno espumoso de las olas. Hay dentro de ellas una marina apoteosis de gloria" (MRD 169). Esa técnica de ola (de la que también hablará en el Darío del 40: "Su misma técnica era marina. Modelaba el verso con plástica de ola" MRD 44) es la musicalidad y la plasticidad que el verso dariano trae a la acartonada poesía postromántica en español, la naturalidad profunda, aprendida del ritmo del cosmos.

Tras la vuelta de Darío a París, Juan Ramón no dejó de insistirle en que lo que debía terminar era su nuevo poemario. El epistolario entre ambos es la mayor fuente de información sobre lo que tras varias dudas se llamó Cantos de vida y esperanza. Los Cisnes y otros poemas, cuya publicación se concretó durante la nueva estancia de Darío en Madrid entre febrero y julio de 1905. Se ha discutido el grado de 
intervención de Juan Ramón. Recuerdo que éste nunca dio muchos detalles del asunto ni se atribuyó otra responsabilidad que la puramente recopilatoria, organizativa y tipográfica, y apunto una hipótesis que, creo, no se ha señalado. En algún momento, algo antes de la publicación de Cantos, Juan Ramón pensó que Antonio Machado (a quien en el libro va dedicado el soneto "Caracol") y él, discípulos españoles predilectos, podían presentar, incluso prologar el libro. Como posibles prólogos interpreto el poema de Machado "Al maestro Rubén Darío. Con motivo de la próxima publicación de sus Cantos de vida y esperanza", cuyo autógrafo Juan Ramón conservó (MRD 212), y la prosa inédita de éste que comienza "Había oído a Dios en el bosque, había visto a Venus en el mar, a Caupolicán en la Pampa, a Hugo en su plaza, a Verlaine en su jardín y, al llegar a España..." (MRD 171). Se trata de una caracterización y de una defensa frente a Rodó y a Unamuno, en la que el Darío de Cantos, su "libro grande y maduro", es presentado como poeta universal y total, americano, francés y español, religioso y pagano, culturalista y natural, sensual y sentimental. Es también el escrito en que por primera vez Juan Ramón identifica a Venus como diosa reina de la mitología dariana.

Con Cantos, con el "triunfo" definitivo de Darío y del modernismo en España, terminó prácticamente la colaboración y el intercambio de favores entre ambos. Darío volvió nuevamente a París y Juan Ramón se retiró a Moguer. Nunca volvieron a verse, ni aun cuando Darío volvió a Madrid como Ministro de Nicaragua. Comenzó un gradual distanciamiento, y el trato, aunque cordial, se fue haciendo intermitente e indirecto. Con todo, ambos fueron los poetas de mayor presencia en Renacimiento, la revista que sustituyó a Helios y donde Darío adelantó otra serie de poemas marinos escritos en la isla de Mallorca que enseguida pasaron a El canto errante. En el recuerdo de Juan Ramón, estos poemas ("!Eheu!, "'Epístola a Madame Lugones", "Hondas"...) llegaron a superponerse a los escritos en Andalucía, y en el Darío del 40 dirá: "Siempre fue para mí mucho más ente de mar que de tierra [...] En España, lo sentí vivir más por Málaga, por Mallorca. Desde ellas me envió ramos de versos. Madrid lo cerraba y lo enroscaba hipnotizado como una serpiente marina" (MRD 43). Posiblemente tampoco pasaría desapercibido a Juan Ramón el artículo que el hoy olvidado pero entonces influyente escritor y crítico Andrés González Blanco dedicó a El canto errante:

(Darío) necesita refrescarse de cuando en cuando. El ambiente irrespirable de los grandes centros urbanos se tonifica con la brisa salobre del mar. Rubén Darío es uno de los poetas marinos. Hay poetas de tierra como Antonio Machado, como Juan Ramón Jiménez. Darío, como D’Annunzio, como el mismo Rueda, es un poeta de mar. Tiene, como todos los que pasan horas contemplando ese mar, una visión de horizontes vastos y una rutilencia espejeante [...] ¡Qué luminoso poeta, oceánico, solar! Es verdaderamente un espíritu mediterráneo [...] En los versos de Rueda hay melodía... en los de Darío hay cierta polifonía: como el mar, la de las 
olas (en Lozano 1978: 126).

Juan Ramón también llegaría a ser un poeta de mar, aunque precisamente a partir de la muerte de Darío y de manera nuevamente diferente a como lo había sido éste. La última referencia que hizo a Darío vivo fue la dedicatoria que preside el libro Melancolía (1912): "A Rubén Darío, melancólico capitán de la gloria” (MRD 186). En ella fija al Rubén melancólico con el que se identificó siempre, y más concretamente al Darío postrero de El canto errante, con sus "Dilucidaciones" ("Toda la gloria y toda la eternidad están en nuestra conciencia"), con su elegiaca "Oda a Mitre" (“¡Oh!, gran capitán de un mundo/ nuevo y radiante...”) y con el soneto final "Los piratas", tan romántico, tan parnasiano y tan sutilmente asociado a los grandes poemas simbolistas del viaje, dedicado a la gloria de "los caballeros del viento", de "los reyes del mar", figura identificable con la del poeta: "Ya es hora de partir, buen pirata, ya es hora/ de que la vela pruebe el pulmón de la racha" (Darío 1967: 767).

La dedicatoria es una anticipada despedida. Juan Ramón recreó casi tantas veces como el encuentro de 1900, el momento en que se enteró de la muerte del maestro: viajando a Nueva York, mientras iba escribiendo el Diario de un poeta recién casado, oyó por radio la noticia y escribió su elegía a Rubén, voz y corazón de América, que empieza: "No hay que decirlo más. Todos lo saben/ sin decirlo más ya. ¡Silencio!" (MRD 163). Juan Ramón interpretó el acontecimiento como la señal de un cambio trascendente. El viaje por mar y el Diario (ese "segundo primer libro mío", al que más tarde retituló Diario de poeta y mar), significaron una transformación - muerte y resurrección - no sólo personal sino histórico literaria: el siglo XIX cedía paso al XX, el simbolismo crepuscular al simbolismo moderno, Darío, antiguo maestro de los jóvenes, al nuevo Juan Ramón, quien lo sustituyó en la influencia general. Al menos en España, durante la década siguiente Juan Ramón se convirtió en el maestro indiscutido, en el poeta consagrado a su obra, a depurar y renovar el legado simbolista, y al mismo tiempo en el poeta volcado en animar y seleccionar a los nuevos que con el tiempo serían conocidos como generación del 27.

Ahora bien, ya entonces había algo no dicho: un doloroso desacuerdo de Juan Ramón con la trayectoria final de Darío, en la que consideraba que éste había claudicado de las exigencias de la pura poesía, un desacuerdo que se insinúa en su silencio casi completo de esos años, incluso en ese severo pero piadoso silencio del que habla su poema fúnebre. Sólo el cariño a Rubén, pero también su insobornable fidelidad a la verdad de la poesía, hicieron que Juan Ramón callase, que no escribiese una necrológica o que no se sumase al homenaje colectivo La ofrenda de España a Rubén Dario de 1916. A todo ello alude en el Darío del 40:

Y la silueta posible de su muerte me dolía, al querer escribirla, como cuando, yendo yo de España a New York, 1916, febrero crudísimo, me 
dolió el radio con la noticia lamentable, frente a Terranova ciego de ciclón blanco en la tarde; en un vano de la ruta que él, un poco vivo aún en sí, había ocupado antes (MRD 43).

Es un silencio que no se rompió hasta 1923, con ocasión de una polémica en la que Juan Ramón intervino - esa fue su expresión- "Contra y por Rubén Darío". La cosa comenzó cuando una improvisada y pomposamente denominada "Junta Suprema de Patronato del Primer Congreso de Juventudes Hispanoamericanas" solicitó a Juan Ramón colaborar en el proyecto de erección en Madrid de una estatua a Darío. El poeta rehusó en una carta durísima, en la que volvió a mostrar su terrible faz de polemista. Comienza manifestando su desagrado por "estos asuntos de hispanoamericanismo de oficio, liceo y junta suprema", y termina proponiendo otro monumento a Darío: "la edición perfecta, sólida, sencilla, definitiva, que digo, de su obra buena". En medio se explaya en la falsa popularidad, en la barata gloria en que cayó Darío en su "turbio ocaso":

Si el poeta, al final de su traqueteada y triste existencia, cayó un poco — por sinrazones sólo disculpables "en él", que tanto tenía de razón alta- en ciertos nauseabundos beleños de patrioterías, academicismos y compadreo fácil, la obligación de quienes lo admiramos de veras es no hundirlo más — con la pesada mortaja de un uniforme que él se puso a veces, inconscientemente, como un niño- en ellos; sino levantarlo, en una purificación de respetuoso 'olvido transitorio" " [...] El Rubén Darío que tenemos la ineludible deuda de perpetuar en esta España que tales pruebas le mereció de exaltación y cariño, no puede ser insisto, porque será necesario insistir mucho en esto- ese Rubén Darío tan manoseado por ahí, de revista cuché y latina de modas, turné de ballena indefensa, postal, álbum, abanico y ¡ay! prólogo de compromiso diplomático o periodístico [...], sino el otro, mejor, el 'uno', arisco y desnudo, de la mar, la carne y el cielo (MRD 148).

"Contra y por Rubén Darío" es uno de los "asuntos ejemplares", de "ética estética", en los que Juan Ramón se creyó obligado a pronunciarse en estos años. También hay que situarlo en su correspondiente contexto histórico y literario. Creo que el ataque de Juan Ramón al "turbio hispanoamericanismo" —otra vez la palabra turbio: no puro, no espiritual-, responde a la instrumentalización política que de esta ideología estaba haciendo la recién estrenada dictadura del general Primo de Rivera (hay sibilinas alusiones de Juan Ramón a los "vividores generales" $M R D$ 150), y que su propuesta de editar dignamente a Darío se explica por la situación en que estaban la crítica y las ediciones darianas. La influencia y los réditos de Darío habían caído en manos de lo que Juan Ramón llamaba los "amigos peores", que no contribuían sino que se aprovechaban de la "gloria" de aquel, representantes del modernismo menguante, industrializado o popularizado, como Vargas Vila, al que detestaba, o del mencionado González Blanco, que ese mismo 
año estaba comenzando a dirigir junto a Alberto Ghiraldo una irresponsable edición de la Obra Completa de Darío. En medio de la polémica, y de acuerdo con Alfonso Reyes y Enrique Díez Canedo, "amigos mejores", Juan Ramón anunció en la Biblioteca de Índice Cartas y versos a Juan Ramón Jiménez de Rubén Dario, una recuperación y una evolución de su viejo proyecto de libro sobre su primer maestro. Y sobre todo, por primera vez, abiertamente, Juan Ramón distingue críticamente y se pronuncia contra el peor, el más fácil Darío, el Darío del rubendarismo, y a favor del mejor y más exigente, de quien se sigue considerando heredero. Nótense las imágenes, que reaparecerán en el retrato del 40 , de la ballena desorientada y del uniforme frente a las del Darío desnudo, "de la mar, la carne y el cielo".

No cabe aquí entrar en detalle en los años 30, fundamentales para que Juan Ramón ampliase su perspectiva sobre la modernidad poética en español. Su colaboración en la gran Antología de la poesía española e hispanoamericana (1934) de Federico de Onís, donde se caracteriza al modernismo como época, época en la que la literatura hispanoamericana alcanza su efectiva independencia y la española vive su segundo renacimiento, y donde Darío y él son los polos ordenadores; sus artículos necrológicos nada convencionales sobre el limitado y superado Salvador Rueda, el picaresco y desacreditado Villaespesa, y el gran Valle Inclán, en los que vuelve a rememorar sus inicios y sus encuentros con Darío, todo ello le lleva a una revisión histórico crítica sobre el modernismo y sobre la función que en él cumplió Darío. Su concepción aparece adelantada en una entrevista al periodista Ángel Lázaro, "Proel", de 1935:

Lo que se llama Modernismo no es cosa de escuela ni de forma, sino de actitud. Era el encuentro de nuevo con la belleza, sepultada durante el siglo XIX por un tono general de poesía burguesa. Eso es el Modernismo: un gran movimiento de entusiasmo y libertad hacia la belleza.

- Rubén Darío fue el capitán, ¿no es eso?

- Hay el Darío universal que yo defiendo, y hay el Darío de lo exótico y lo castellanista [...] Queda el gran Darío. Ése está vivo en todos los poetas actuales (Jiménez 2013: 203).

Pero hay que añadir que ya para entonces, en realidad desde 1927 hasta al menos 1941, su visión estuvo condicionada, y deformada, por su encarnizado enfrentamiento con los poetas del 27 que él había prohijado. Una pelea ideológica, estética y sobre todo personal que tuvo uno de sus picos en 1934, cuando se sumó a ella Pablo Neruda, cónsul de Chile en Madrid, simbólicamente hermanado con Lorca y sus amigos a través del padre y maestro mágico Darío, no a través del "puro" y pronto injustamente menospreciado Juan Ramón. Por entonces Juan Ramón concibió también otro proyecto inacabado, que ya no abandonará durante su largo exilio americano, de un gran libro sobre el modernismo, del que nacieron la serie de conferencias Alerta y el curso sobre el modernismo de Puerto Rico 
(Jiménez 1983 y 1962), un libro que sería su testamento crítico, "el intento de una visión total y verdadera de este gran movimiento, mezcla de verdad y de mentira; verdad que, salvada de la mentira, integra para mí toda la poesía y literatura mejor españolas e hispanoamericanas, de lo que va de siglo" (en Díez Canedo 1943: 137142). Estas serían las coordenadas finales en las que situar su Rubén Darío del 40.

"Rubén Darío (1940)" fue preparado expresamente para Españoles de tres mundos, una colección de retratos que Juan Ramón calificó de "panorama de mi época", "salón de mi recuerdo", "plaza de mi imaginación", en la que historia, crítica y autobiografía quedan unidas y transformadas por el recuerdo, la imaginación y la escritura (cfr. Blasco y Díaz de Castro 2005: 3-49). El dedicado a Rubén está construido como un desarrollo metafórico e intertextual de imágenes presentes en sus escritos anteriores, de poemas marinos de Darío, así como de cierta iconografía dariana. Su método es dual, lírico e irónico, y al hablar del Darío humano, demasiado humano, el retrato se convierte en caricatura e introduce la deformación pero sin llegar a lo grotesco:

Rubén Darío andaba siempre mareado de la ola, de la Venus, de la sal, del tónico. No sabía nunca qué hacer, así, con su levita, sus guantes, su sombrero de copa, y menos con su disfraz diplomático. No eran éstos sus trajes ni como favorito plenipotenciario de su reina oriental, ni como almirante de su dios Neptuno. Él tenía colgado en la percha de su pensión su desnudo mayor. Por eso lo encontraron a veces caído en la acera; se enredaba en el uniforme (MRD 44).

La dualidad entre el auténtico y el falso Darío se concreta en la metáfora, esencial en la poética juanramoniana, de lo desnudo y lo vestido, ésta última en la forma de uniforme o disfraz diplomático, lo que remite a la famosa fotografía de Darío Embajador en Madrid, en la que éste "estalla sus galas diplomáticas brillosas" (Jiménez 1981: 83) ${ }^{2}$.

${ }^{2}$ Cabe adjuntar aquí algunos comentarios más, no muy diferentes al de Juan Ramón, que ese famoso "uniforme" ha suscitado, y que Erick Blandón resumía recientemente así: "A propósito de esa imagen en traje de embajador que - impresa en afiches y vallas con los rasgos faciales alterados - se ha convertido en objeto kitsch de la plástica y la gráfica nicaragüense, Salomón de la Selva recordaba a Darío como aficionado a la pompa y ceremonia diplomática [...]. Por su parte, David Whisnant dice que ese elegante vestido apenas puede ser visto como una metáfora de los débiles lazos entre Darío y Nicaragua, los cuales no fueron fortalecidos por la respuesta de los sucesivos gobiernos nicaragüenses a su creciente prestigio y fama, y que refleja la ambivalencia política ante los repetidos intentos que hizo para obtener respaldo. En otras palabras, ese traje vendría a ser el significante de los ultrajes, indiferencias, manoseos y manipulaciones a que los poderes reales y simbólicos expusieron, en vida y después de muerto, al letrado de mayor relieve en la historia de Nicaragua" (Blandón 2011: 19-20). 


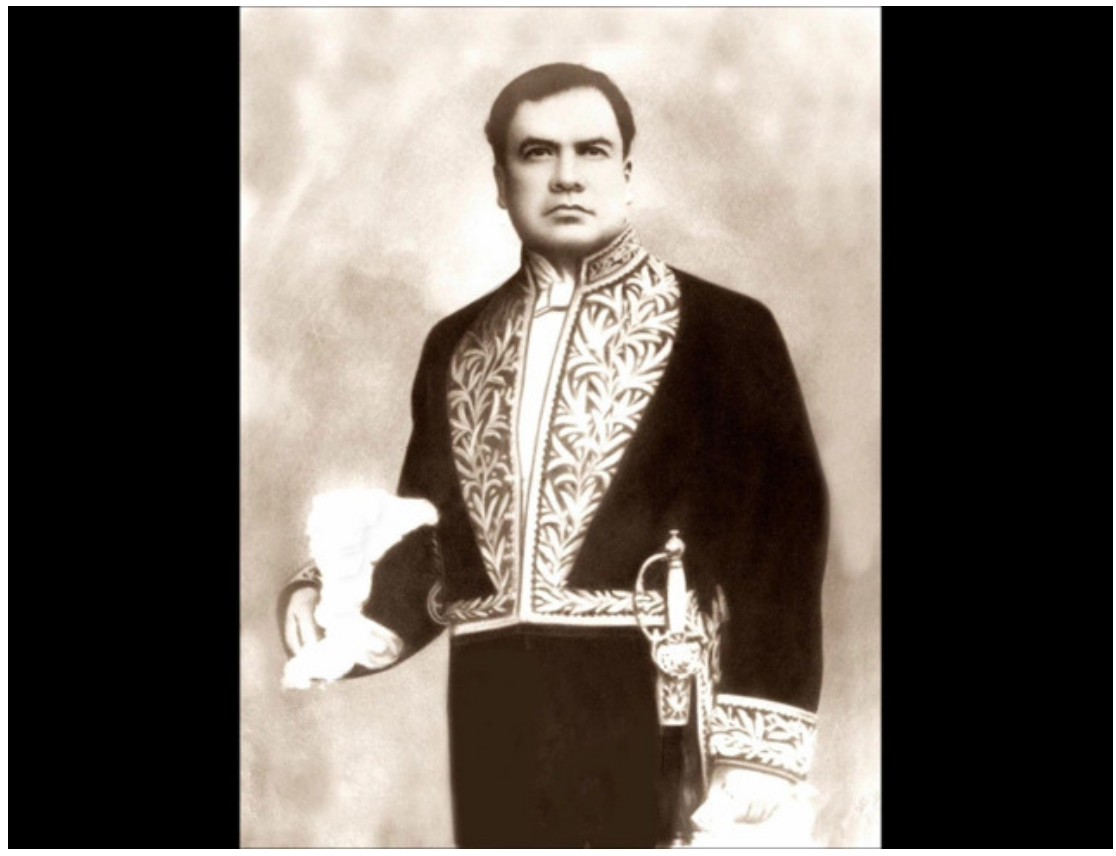

Además Darío aparece mareado, náufrago, perdido. Pero nunca del todo. El Darío de Juan Ramón se salva gracias a un instinto de Belleza que lo devuelve al rumbo espiritual y que aparece simbolizado en una brújula, en el caracol donde se oye el corazón y el mar, y sobre todo en la diosa Venus, que para Darío es un astro y para Juan Ramón es también una isla:

Siempre Venus, vigilándolo, desde la juventud, mujer isla del espacio verde: ... Venus, desde el abismo, me miraba con triste mirar...

En su segura transfiguración, Rubén Darío habrá sido destinado por sus divinidades paganas (entre las que asomó Cristo como un curioso de su alma, tierna visita que él agradeció tanto) a una isla esmeralda. Isla verde transparente, ovalada en el poniente del mar cerúleo, gran joya primera y última, perenne apoteosis tranquila de la esperanza cuajada. Que él vio la eternidad también como isla sinfónica final del poniente cotidiano, y lo inmortal lo esperó como espera al nostáljico navegante (MRD 45).

Darío ("En la isla en que detiene su esquife el argonauta/ del inmortal ensueño...”, 1967: 572) queda así exaltado en su paraíso de Belleza perdida y reencontrada, purificado y completado, vivo en su poesía mejor (vivo en el propio Juan Ramón), cósmicamente fundido con el "tesoro marino total", señalando el rumbo a los demás poetas: "Rubén Darío — termina—, ministro tú, mejor que otro, 
de los capitanes del viento" (MRD 45).

Mejor, por cierto, que qué otro. Pienso en Neruda, en el poeta cónsul, en el poeta oceánico, en el para Juan Ramón "gran mal poeta". Poco después Juan Ramón empezó si no a rectificar sí a matizar sus opiniones sobre Neruda, a reconocerlo como "el poeta más poderoso de Hispanoamérica, después de Rubén Darío", el cuarto de "los influyentes mayores", después de éste, Juan Ramón y Lorca (Jiménez 1983: 83). Una nota al margen: para entonces el joven Octavio Paz comenzó su polémica con Neruda (otro avatar del tema del maestro y del discípulo), usando como punto de partida a Darío y el retrato de Juan Ramón que, como dije, se publicó en México. En su ensayo "El corazón de la poesía" (1943) Paz se defendió de los ataques que Neruda le lanzó a él y a los europeístas y descomprometidos poetas mexicanos de Contemporáneos amparándose en la universalidad de Darío, y caracterizando así a este:

El poeta de Cantos de vida y esperanza no sólo es el inventor del modernismo sino, por encima de todo, el padre de la poesía moderna en español. Su poesía es como un corazón que alimenta con su sangre a todos los poetas que le suceden en el tiempo [...] Todos viven en él. Su corazón los concentra y su palabra los empuja. Unos son piedra, otros el cielo, el viento, el fuego; él es el mar. Su corazón es una caracola y en ella, junto al latido de su corazón, oímos el flujo y reflujo infinitos del mar, el latido inagotable de las aguas primeras, origen de la vida. Esa caracola es un testimonio de nuestro nacimiento y en ella están inscritos los signos de nuestro destino (Paz 1988: 353-354).

Una visión que Paz renovó y profundizó veinte años después, en "Rubén Darío. El caracol y la sirena" (1964), el ensayo que abrió las puertas al redescubrimiento académico del esoterismo modernista (García Morales 1999: 637-657).

$\mathrm{Y}$ termino con un último aspecto del retrato, con un detalle en el que recuerdo, imaginación y realidad acaban extrañamente confundidos. Desde el comienzo Juan Ramón Jiménez dice inspirarse en una foto o, mejor, en el recuerdo (pues tras la Guerra Civil no tiene a mano muchos de sus documentos) de una foto de Darío que hacía años le regaló Alfonso Reyes, "amigo siempre mejor de Rubén Darío", y en la que Darío aparecía “en uniforme blanco veraniego, de ¿capitán de navío?" (MRD 43). Juan Ramón usó como base para algunos de sus retratos literarios darianos fotografías y cuadros conocidos del escritor ${ }^{3}$. Pero esa fotografía del Darío en

${ }^{3}$ En una de las ordenaciones posibles de Mi Rubén Darío (MRD 19-20; Crespo 1981: 68), éste iba explícitamente acompañado de imágenes del poeta como el retrato a lápiz de Vázquez Díaz, o la fotografía que Darío dedicó a Archer M. Huntington en Nueva York en 1915, a la que Juan Ramón alude en "Rubén Darío (1940)" como "su fotografía final con firma aún segura y redonda" (MRD 43). En el nostálgico e imaginativo (auto)retrato "Rubén Darío español" habla de sus acercamientos a Darío antes de conocerlo personalmente, lo 
uniforme de marino parece que no existe, y es muy posible que la confundiese con otras, como las de Darío vestido de blanco en su retorno a Nicaragua de 1908.

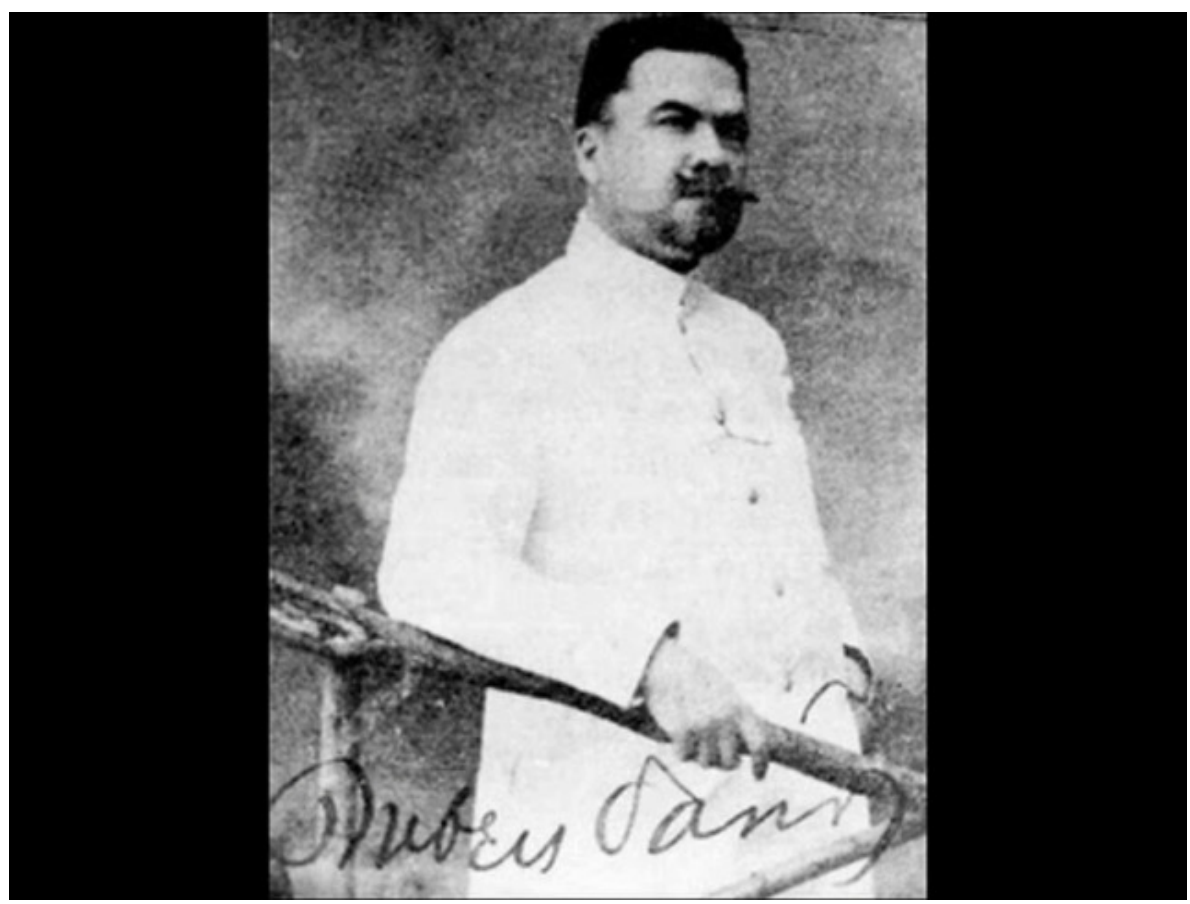

Y sin embargo... Sin embargo en 1944 Juan Ramón accedió a grabar unas palabras, que se trasmitieron por radio, con ocasión de la botadura en Savannah, Georgia, del buque de la armada norteamericana bautizado con el nombre de "Rubén Darío".

mezcla con sus recuerdos moguereños de los años "americanos" 1892 y 1898 , y lo asocia a las efigies de Antonio Maceo, el líder independentista cubano, muerto en el 96: "yo le veía a Maceo muerto la cara que tenía Rubén Darío en la antología de Montaner y Simón" (MRD 53). Se refiere al grabadito del poeta que apareció en Antología Americana (Barcelona, Montaner y Simón, 1897, p. 107), pero pienso que es más probable que la asociación se la suscitaran fotografías y grabados del Darío juvenil, como el que preside la segunda edición de Los raros, de 1905, que tiene, efectivamente, un llamativo parecido con Maceo. 


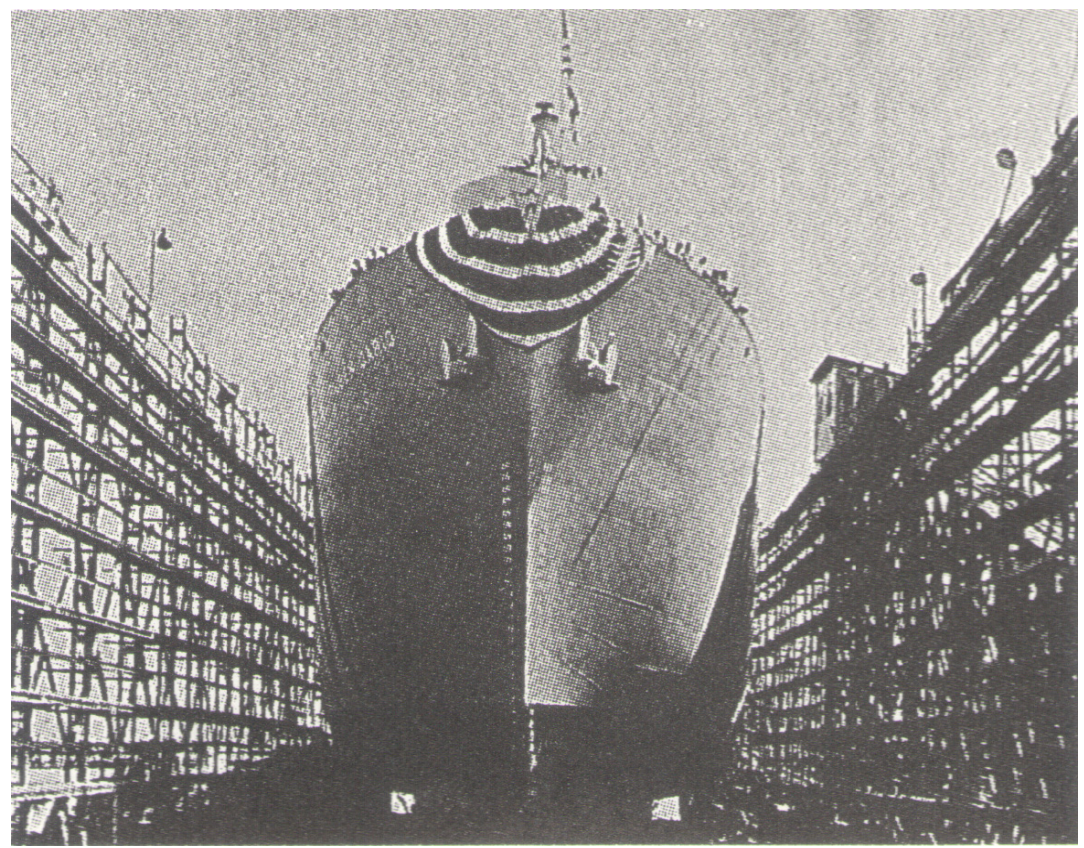

Botadura del barco de la Armada norteamericana "Rubén Darío" en Savannah, Georgia, USA, 22 junio 1944 (Archivo Sala Zenobia Juan Ramón, Universidad Río Piedras, Puerto Rico. Reproducido en Poesía. Revista ilustrada de información poética, n 34-35, Monográfico Rubén Darío, Madrid, Ministerio de Cultura, 1991).

Era el final de la Segunda Guerra Mundial y él creyó contribuir así a una obra de concordia interamericana que favorecía la causa aliada. En la alocución volvió sobre su idea - "Rubén Darío fue ante todo y siempre un poeta marino. Lo mejor de su obra está hundido, bañado, mecido o salpicado de mar"-, y sobre lo de la fotografía:

Me complazco ahora, con mi imaginación, en embarcar a Rubén Darío, vestido de blanco como en la fotografía, en el Liberty ship que lleva su fastuoso nombre. Que con el poeta en su puente, salga al Atlántico el buque y sea saludado por los coros de delfines y recibido al anochecer de Savannah por esta Venus, 'luciente tembladora', de junio" (MRD 88).

Juan Ramón ignoraba otras cosas más "turbias" que estaban tras ese acto, como la instrumentalización de la imagen de Darío que realizaba el régimen somocista (Whisnant 1992: 25 y passim). Tampoco sabía que desde hacía tiempo circulaba en Nicaragua la leyenda de que Darío en un viaje o visita a un barco se había fotografiado vestido de capitán de marina ¿norteamericano? Ni supo, en fin, que a alguien se le ocurrió hacer de alguna manera realidad esa historia y con ello, su 
fotografía recordada o soñada, y que ésta terminó presidiendo el salón principal del barco "Rubén Darío". Agradezco al siempre generoso Jorge Eduardo Arellano el obsequio que hace años me hizo de la portada de la revista nicaragüense Orto, en la que apareció ese montaje fotográfico del Darío marino ${ }^{4}$.

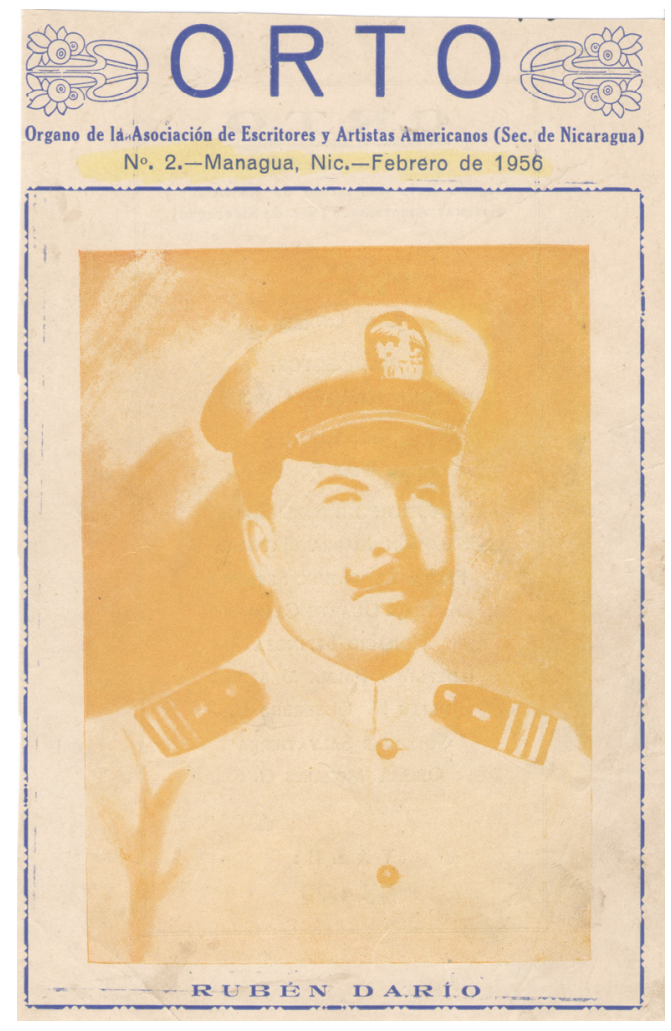

${ }^{4}$ El retrato apareció con una nota editorial: "En el salón principal del Barco de la Libertad 'RUBÉN DARÍO' se exhibe un retrato del gran poeta nicaragüense, enviado por el señor Adán Díez F. al doctor Guillermo Sevilla Sacasa, Embajador de Nicaragua en los Estados Unidos, quien a su vez lo obsequió al Ministerio de Estado de los Estados Unidos. Este retrato de Darío, completamente desconocido, es creación del Estudio Díaz F. e hijas, de Managua. Darío aparece en uniforme americano como Capitán de Corbeta, pues existe la historia de que en uno de los viajes del Poeta, o visita que hiciera a un Barco Americano, en calidad de broma los admiradores del genial revolucionario de la Lírica, lo designaron con el Título de Capitán de Marina. Hay la creencia de que le fue tomada una fotografía, la cual no se ha conseguido. Con esta anécdota del Poeta, el Estudio Díaz F. tuvo la ocurrencia de transformar una fotografía del Darío que le fuera tomada hace algún tiempo en Managua, la que aparece hoy con uniforme de Capitán de Corbeta. La fotografía es real, pero transformada como dejamos dicho" (“El retrato...”: 40-41). 


\section{BIBLIOGRAFÍA}

BLANDÓN GUEVARA, Erick.

2011 Discursos transversales. La recepción de Rubén Dario en Nicaragua. Managua: Banco Central de Nicaragua.

BLASCO, Javier y Francisco J. DÍAZ DE CASTRO.

2005 "Introducción" a Juan Ramón Jiménez, Libro de retratos, en Obra poética, Tomo 4. Ed. Javier Blasco y Teresa Gómez Trueba. Madrid: Espasa Calpe, pp. 3-49.

CRESPO, Ángel.

1981 "Los Rubén Darío de Juan Ramón Jiménez", en Pilar Gómez Bedate (ed.). Estudios sobre Juan Ramón Jiménez. Puerto Rico: Recinto Universitario de Mayagüez, pp. 47-87.

DARÍO, Rubén.

1938 Poesias y prosas raras. Ed. Julio Saavedra Molina. Santiago: Universidad de Chile.

1967 Poesías completas. Ed. Alfonso Méndez Plancarte y Antonio Oliver Belmás. Madrid: Aguilar.

1998 España contemporánea. Ed. Noel Rivas Bravo. Managua: Academia Nicaragüense de la Lengua.

2001 Tierras solares. Ed. Noel Rivas Bravo. Managua: Fondo Editorial CIRA.

DÍEZ CANEDO, Enrique.

1944 Juan Ramón en su obra. México: El Colegio de México.

"El RETRATO DE DARÍO EN NUESTRA CARÁTULA"

1956 Orto. Órgano de la Asociación de Escritores y Artistas Americanos (Sec. Nicaragua), Managua, (2), pp. 40-41.

García Morales, Alfonso.

1999 “'El caracol y la sirena' de Octavio Paz: una lectura 'surrealista' de Rubén Darío", Anales de literatura hispanoamericana, $\mathrm{n}^{\circ}$ 28, pp. 637-657.

2014 "Helios, Juan Ramón Jiménez y 'siempre, más lejos o más cerca, Rubén Darío", en Rocío Oviedo Pérez de Tudela (ed.). Rubén Dario en su laberinto. Madrid: Verbum, pp. 6-21.

García Morales, Alfonso y Rosa García GUTIÉRREZ.

2002 'El 'Atrio' de Rubén Darío y otros ecos de la fraternidad modernista hispanoamericana en Ninfeas", en Eloy Navarro Domínguez y Rosa García Gutiérrez (eds.). Unidad. Monográfico sobre Ninfeas y Almas de violeta. Juan Ramón y la poesía hispánica en torno a 1900. Huelva: Fundación Juan Ramón Jiménez, pp. 41-90.

GUERRERO RUIZ, Juan.

1999 Juan Ramón de viva voz, 2 vols. Valencia: Pre-textos/ Museo 
JIMÉNEZ, Juan Ramón.

\section{Ramón Gaya.}

1962 El modernismo. Notas de un curso (1953). Ed. Ricardo Gullón. México: Aguilar (Nueva ed. de Jorge Urrutia. Madrid: Visor, 1999).

1981 Prosas críticas. Ed. Pilar Gómez Bedate. Madrid: Taurus.

1983 Alerta. Ed. Javier Blasco. Salamanca: Universidad.

1990 Mi Rubén Darío. Ed. Antonio Sánchez Romeralo. Huelva: Fundación Juan Ramón Jiménez.

2006 Epistolario I (1898-1916). Ed. Alfonso Alegre Heitzmann. Madrid: Residencia de Estudiantes.

2013 Por obra del instante. Entrevistas. Ed. Soledad González Ródenas. Sevilla: Fundación José Manuel Lara.

LOZANO, Carlos.

1978 La influencia de Rubén Dario en España. León, Nicaragua: Universidad Nacional Autónoma de Nicaragua.

MEJÍA SÁNCHEZ, Ernesto.

1975 "Otro cuento desconocido de Rubén Darío. 'Historia del mar", El Pez y la Serpiente. Revista de Cultura, n 16, pp. 122-130.

PAZ, Octavio.

1988 Primeras letras. Ed. Enrico Mario Santí. Barcelona: Seix Barral. SOLAR, Alberto del.

1917 "Rubén Darío y el océano", en Rubén Darío. Ramillete de reflexiones (Obra inédita). Madrid: Librería de Sucesores de Hernando, pp. 169-176.

WHISNANT, David E.

1992 "Rubén Darío as a Focal Cultural Figure in Nicaragua: The Ideological Uses of Cultural Capital", Latin American Research Review, vol. 27, $\mathrm{n}^{\circ} 3$, pp. 7-49. 